\title{
Update on the "Dutch hypothesis" for chronic respiratory disease
}

\author{
Jørgen Vestbo, *Eva Prescott
}

Medical Department, Amager Hospital, Italiensvej 1, DK-2300 Copenhagen S, Denmark and *Institute of Preventive Medicine, Kommunehospitalet, DK-1399 Copenhagen K, Denmark

Introductory article

Airways responsiveness and development and remission of chronic respiratory symptoms in adults

X Xu, B Rijcken, JP Schouten, ST Weiss

Background. Many patients with chronic obstructive lung disease show increased airways responsiveness to histamine. We investigated the hypothesis that increased airways responsiveness predicts the development and remission of chronic respiratory symptoms. Methods. We used data from 24-year follow-up (1965-90) of 2684 participants in a cohort study in Vlagtwedde and Vlaardingen, Netherlands. Increased airways responsiveness was defined as a $P C_{10}$ value (concentration of histamine for which challenge led to a $10 \%$ fall in forced expiratory volume in $1 \mathrm{~s}$ ) of less than $8 \mathrm{mg} / \mathrm{ml}$. Information on respiratory symptoms was collected by means of a standard questionnaire every 3 years. Logistic regression was used to control for age, area of residence, cigarette smoking status, and sex. Findings. Participants with increased airways responsiveness (1281 observations) were more likely than those without increased airways responsiveness (5801 observations) to develop the following symptoms during any 3-year follow-up interval: chronic cough (odds ratio 1.9 [95\% Cl 1.2-2.9]), chronic phlegm (2.0 [1.3-3.0]), dyspnoea (2.3 [1.5-3.5]), asthmatic attacks (3.7 [2.2-6.1]), and persistent wheeze (2.7 [1.7-4.4]). The estimate of the odds ratio for the development of any of the six symptoms was 1.7 (1.2-2.3). Participants with increased airways responsiveness were less likely than those without this characteristic to show remission of these respiratory symptoms. The estimate of the odds ratio for the remission of any of the six symptoms was $0.42(0.28-0.61)$. Interpretation. These prospective analyses show that increased airways responsiveness is positively associated with the development of chronic respiratory symptoms and negatively associated with the remission of these symptoms in adults. (Lancet 1997; 350:1431-34)

The "Dutch hypothesis" was originally put forward by Orie et al. ${ }^{1}$ They postulated that airway hyperresponsiveness (AHR) and atopy were markers of a basic disturbance or constitution which predisposed to the development of chronic non-specific lung disease characterised by cough, sputum production, dyspnoea, and often airflow limitation. This disease, later termed CARA in Dutch, included both chronic asthma and CARA in Dutch, inclich and what we would today label as chronic obstructive pulmonary disease (COPD). Retrospectively, it seems tha this lack of distinction between asthma and COPD - at a time when most British, other European, and American studies made a clear distinction - was a major hindrance for communication between the Dutch group and others. Also, the "Dutch hypothesis" was not a term proposed by Orie et al but by others contrasting it with the "British hypothesis" which focused on chronic mucus hypersecretion as a marker of recurrent airway infections causing chronic airflow limitation.
The core point at the beginning of the 1960s was that the Dutch hypothesis pointed to endogenous factors which might play an important role in the development of COPD. This contrasted with the view that exogenous factors-particularly tobacco smoke-were the overwhelming causes of COPD.

Atopy, airways hyperresponsiveness, and the risk of COPD

The role of atopy has gradually been separated from that of AHR, at least in epidemiological studies. In several studies total IgE has been used as a marker of atopy. In general, smokers have an increase in total IgE and also in blood eosinophil count compared with nonsmokers. In the absence of clinical asthma there is, however, no indication that atopy interacts with tobacco 
smoking, and atopy is not believed to be a true risk factor for COPD. ${ }^{23}$

The other endogenous component of relevance is believed to be AHR. This has been the focus of increasing research within the last few years since various refinements of the diagnostic provocation procedures have enabled measurement of AHR in large studies, both in population studies to evaluate epidemiology ${ }^{3}$ and in the area of randomised clinical trials..$^{4-6}$ Due to minor and somewhat dubious differences, ${ }^{78}$ histamine seems to have been favoured over methacholine in studies on COPD.

AHR is clearly related to the presence of pulmonary symptoms ${ }^{10}$ and level of lung function. ${ }^{10-13}$ This has been known for years but often provokes no more than a "chicken and egg" discussion as histamine or than a "chicken and egg" discussion as histamine or
methacholine tests in chronic airflow obstruction invariably suggest AHR for geometric reasons alone. The association between forced expiratory volume in on second $\left(\mathrm{FEV}_{1}\right)$ and apparent AHR deserves careful attention ${ }^{1415}$ and there is a need for a consensus on the most appropriate way of taking airway calibre into account before there is any attempt to quantify the leve account before there is any attempt to quantify the level
of airway responsiveness. A detailed discussion of this of airway responsiveness. A detailed discussion of this
methodological issue is, however, beyond the scope of this review.

AHR has also been shown to be an independent risk factor for an accelerated decline in $\mathrm{FEV}_{1}$ in a number of large cohort studies including a study originating from the Groningen group, ${ }^{16}$ a study by Villar et al in the elderly, ${ }^{17}$ and the Normative Aging study. ${ }^{18} 19$ in the elderly, and the Normative Aging study.
Furthermore, an association between AHR at baseline Furthermore, an association between AHR at baseline
and five year decline in $\mathrm{FEV}_{1}$ was present in the Lung Health Study. ${ }^{6}$ The apparent impact of AHR on the decline in $\mathrm{FEV}_{1}$ has varied between studies, but on average the presence of AHR appears to add approximately $10 \mathrm{ml} / \mathrm{year}$ to the decline in $\mathrm{FEV}$. The effect is largest in populations of elderly subjects. ${ }^{17} \mathrm{~A}$ review of the epidemiological literature on AHR and the decline in $\mathrm{FEV}_{1}$ has been made by Rijcken and Weiss, ${ }^{20}$ co-authors of the introductory article.

The above studies all looked at lung function data measured on two or more occasions, the first with concurrent measures of AHR and $\mathrm{FEV}_{1}$. With subsequent $\mathrm{FEV}_{1}$ measurements the initial $\mathrm{AHR}$ from such studies can be related to the change in $\mathrm{FEV}_{1}$. If it explains a significant part of the $\mathrm{FEV}_{1}$ variation, the hypothesis that AHR is a risk factor for an excess FEV hypothesis that AHR is a risk factor for an excess $\mathrm{FEV}_{1}$
decline is supported. Although analysing this decline in decline is supported. Although analysing this decline in
$\mathrm{FEV}_{1}$ is not without pitfalls, ${ }^{21}$ an association between AHR and subsequent $\mathrm{FEV}_{1}$ decline now seems established. It should be noted, however, that AHR - like all other biological phenomena-varies over time. A given threshold may lead subjects to be labelled "hyperreactive" at some times and "normal" at others. For reactive" at some times and "normal" at others. For
this reason there is a need for studies which are able to this reason there is a need for studies which are able to
look at changes in AHR and changes in $\mathrm{FEV}_{1}$ as well look at changes in AHR and changes in $\mathrm{FEV}_{1}$ as well
as other disease outcomes in order to demonstrate consistency.

\section{The introductory article}

The introductory article by $\mathrm{Xu}$ and colleagues stems from an almost ideal cohort study which has measured AHR every third year for a 24 year period in the rural Vlagtwedde and urban Vlaardingen populations of Holland. Increased airways responsiveness to histamine was defined as a provocative concentration causing a fall in $\mathrm{FEV}_{1}$ of $10 \%$ or more $\left(\mathrm{PC}_{10}\right)$ of $<8 \mathrm{mg} / \mathrm{ml}$. Subjects with increased airways responsiveness were more likely than subjects without to develop a variety of respiratory symptoms (chronic cough, chronic sputum expectoration, dyspnoea, asthmatic attacks, persistent wheeze) in any following three year period (odds ratios of 1.4-3.7 adjusted for age, sex, smoking status, and asthma-like symptoms, attacks than for "bronchitis" which was defined as episodes of cough and phlegm lasting for at least three weeks in the past three years. Furthermore, patients with increased airways responsiveness were less likely to report remission of symptoms than those without increased responsiveness.

The strength of the study lies in its sample size, its two distinct cohorts, and the appropriate use of advanced statistical methods. It does, however, have one limitation. The results were said to be uninfluenced by the exclusion of "asthmatics" but no definition of the latter was provided. Presumably the authors relied on selfreported physician made diagnoses. The relationship between AHR and the clinical symptoms of asthma is well founded and so the inclusion of asthmatic subjects is likely to have introduced some bias. We would have expected, conversely, some weakening of the demonstrated associations after exclusion of asthmatic subjects. The authors have nevertheless collected and analysed invaluable data which strengthen the overall credibility of AHR as an important aetiological factor in chronic respiratory disease.

\section{Airways hyperresponsiveness and other risk}

\section{factors for COPD}

Thus, AHR seems to be an independent risk factor for the development of COPD, presumably acting as a "constitutional factor" as suggested by the Dutch hypothesis. This poses the further interesting question of how the AHR risk links with other established risk factors.

It is worth noting that the clinical diagnosis of COPD is ususally "cross-sectional"- that is, the diagnosis is made after demonstrating irreversible airflow limitation after the apparent exclusion of a few (and rare) specific conditions that can also cause fixed airway obstruction. It is not generally diagnosed after the longitudinal obThe disfrom the clinical history, a history of smoking and other exposures such as dust and fumes, serial measurements of spirometric values or peak flow, measurements of parenchymal lung function, or (when doubt remains) corticosteroid reversibility or the quantification of airway responsiveness. This clinical approach does not always distinguish between the several ways in which the affected individual may have acquired a low level of lung function. ${ }^{20}$ The different possibilities are shown in fig 1 where the normal course of growth and decline in $\mathrm{FEV}_{1}$ is shown.

One of the main obstacles for the acceptance of the Dutch hypothesis has always been the "downgrading" of the role of tobacco smoking. In the literature on COPD the attributable risk of tobacco smoking is generally believed to be $80-90 \%$. At the same time only $15 \%$ of smokers develop COPD, a phenomenon generally ascribed to the presence or absence of various degrees of "susceptibility".

The growth phase for the lungs (or at least lung function) has recently been shown to be affected by smoking, especially in girls, ${ }^{23}$ and from early cross sectional studies it seems that AHR is associated with a 


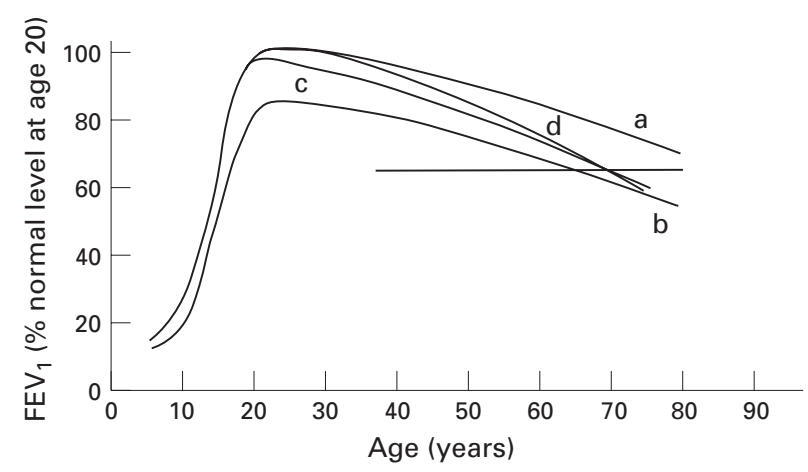

Figure 1 Forced expiratory volume in one second (FEV $V_{1}$ ) as $\%$ of maximal predicted at age 20 against age. Line $a=$ normal decline: line $c=$ = premature or early decline: line $d=$ an accelerated decline in lung function compared with normal subjects (line a). Figure reproduced with permission from Kerstjens et al. ${ }^{22}$

lower maximally attained level of $\mathrm{FEV}_{1}$. The growth pattern is largely unknown, but the association is readily observed in growing children with persistent asthma. ${ }^{24}$ No studies have looked at interactions between AHR and smoking although the growth of lung function seems to be more markedly reduced in symptomatic smokers than in asymptomatic smokers. ${ }^{2}$

It is generally believed that in healthy non-smokers a plateau phase of lung function occurs in early adulthood, generally spanning the ages $25-35$ years ${ }^{25}$ but this belief may be partly the result of combining measurements of may be partly the result of combining measurements of continued slow growth in some subjects with those of
slow decline in others. ${ }^{26}$ Smoking shortens the plateau slow decline in others. ${ }^{26}$ Smoking shortens the plateau phase

Recent work has suggested that, contrary to previous "common knowledge", female gender seems to be a "commer risk factor for COPD 2728 From the viewpoint of the Dutch hypothesis a higher prevalence of AHR in women provides the means for greater susceptibility to the harmful effects of smoking. Such an increased prevalence was reported from the Lung Health Study ${ }^{29}$ but this was initially ascribed to geometric differences in airways calibre. However, subsequent analyses have shown that the difference cannot be explained solely by geometric factors. In a recent French paper Leynaert $e$ $a l^{30}$ found that young women were more hyperreactive $a l^{30}$ found that young women were more hyperreactive
than men. With AHR defined as a provocative dose of than men. With AHR defined as a provocative dose of methacholine causing a $20 \%$ fall in $\mathrm{FEV}_{1}\left(\mathrm{PD}_{20}\right)$ of
$\leq 4 \mathrm{mg} / \mathrm{ml}, 37.3 \%$ of women were hyperreactive and $18.6 \%$ of men. The difference could not be attributed to differences in height. The study also suggested that a larger proportion of the AHR found in women was associated with smoking. This implies that this greater susceptibility to smoking might be mediated by AHR, though the introductory article does not support such a hypothesis.

It is tempting to regard AHR as the marker of susceptibility for COPD, and the study of Leynaert et a supports this. However, larger studies have not been able to demonstrate an interaction between AHR and smoking in analyses of the decline in FEV. If AHR in smokers is important in the pathogenesis of progressive smokers is important in the pathogenesis of progressive
airflow obstruction, epidemiological studies should be airflow obstruction, epidemiological studies should be
able to demonstrate a statistical interaction between able to demonstrate a statistical interaction between
AHR and smoking - a statistical "interaction" being roughly equivalent to clinical "susceptibility". So far no publication has been able to report this, the introductory article being no exception.
While statistical interactions are often treated with little attention, we find this lack of interaction disturbing and we believe it represents a major obstacle to accepting AHR as the underlying marker of susceptibility. Without a demonstrable interaction between AHR and a strong environmental factor such as tobacco smoke, AHR should be seen as no such as tobacco smoke, AHR endent risk factor for COPD along with smoking, rather than as a more fundamental mechanism by which smoking exerts its influence. Another way of demonstrating that AHR and smoking interact in causing airway obstruction would be by determining whether attenuation of AHR can slow down the progression of airflow obstruction in continuing smokers. This is being tested in ongoing studies. At present, however, there is insufficient epidemiological or scientific evidence to regard AHR as the mechanistic pathway for constitutional susceptibility to exogenous factors such as tobacco smoke. Studies focusing on this point are clearly needed.

Chronic mucus hypersecretion has re-emerged as a risk factor for an accelerated $\mathrm{FEV}_{1}$ decline $^{3132}$ and recent ing on lung function in symptomatic than in asymptomatic subjects. ${ }^{25}{ }^{32}$ No studies have looked at interactions between mucus hypersecretion and AHR, and both may represent markers of an inflammatory component in the disease. $^{3334}$

\section{The heterogeneity of COPD and the Dutch} hypothesis

Another impediment to widespread acceptance of the Dutch hypothesis has been the reluctance to accept a common background for diseases with such differing pathophysiology as asthma and emphysema. Instead of rejecting the hypothesis on these grounds it may be worthwhile taking a broader view.

From clinical and pathological studies it is clear that COPD may arise as a consequence of emphysema with destruction of lung tissue and loss of elastic recoil, a dramatic example of this being the terminal phase of $\alpha_{1}$-antitrypsin deficiency. On the other hand, end stage COPD may be seen with virtually no emphysema, the severe airflow limitation being a consequence of small airways dysfunction. This is due to thickening of the airway wall and fibrotic changes following remodelling processes - an obstructive bronchiolitis. With growing recognition of this heterogeneity of COPD (quite apart from COPD + asthma) it is clear that no one hypothesis will be able to fully explain its pathogenesis; it may be fruitful to consider the many pathways to or causes of COPD, or the spectrum of COPD, rather than COPD alone. While it may be appropriate for initial diagnosis and management to regard COPD as a single entity and proceed according to guidelines recently published, ${ }^{35}$ the search for underlying mechanisms needs to lished, ${ }^{35}$ the search for underlying mechanisms needs to
follow other leads. In this respect the Dutch hypothesis can make a valuable contribution.

The close connection between AHR and asthma and its apparent additional relation to COPD requires comment in any update on the Dutch hypothesis. In a further paper to the introductory article, Rijcken et $^{3{ }^{36}}$ argued that distinguishing between asthma and COPD in epidemiology is of little use. This may be so, particularly for studies looking strictly at $\mathrm{FEV}_{1}$ decline or mortality. For the clinician, however, the clinical picture is often distinguishable and it makes sense to separate asthma from COPD in terms of treatment strategies, treatment goals, etc. Nevertheless, the traditional view that lung function in asthma typically remains normal 
LEARNING POINTS

* Airway hyperresponsiveness (AHR) is associated with respiratory symptoms, level of lung function, and decline in lung function.

* Changes in AHR are associated with changes in respiratory symptoms, seemingly in both asthmatic and non-asthmatic subjects.

* AHR is a risk factor for COPD, independent of age and tobacco consumption.

* The reported relationship of AHR with gender needs further evaluation.

* Future studies of respiratory epidemiology may benefit from looking at changes in the risk factor of interest as well as at changes in the outcome variable-for example, the methodology reported in the introductory article.

between asthma attacks is now discarded, and it is generally accepted that processes of airway remodelling often lead to permanent damage to the airway wall and to fixed obstruction. Thus, an increased longitudinal decline in $\mathrm{FEV}_{1}$ can be demonstrated in asthmatic subjects compared with non-asthmatic subjects, ${ }^{37-39}$ just as it can in subjects with COPD. This makes asthma a risk factor for COPD and it supports the conclusions of Lange $e t a l^{40}$ that the increased mortality of subjects with asthma is due in part to COPD

Weiss has suggested that our emerging knowledge of the importance of perinatal factors for the later risk of impaired lung function ${ }^{4142}$ should be combined with experience from research on childheod wheeze, ${ }^{43}$ experience from cognised and unrecognised childhood asthma, and the
above cited studies on AHR and $\mathrm{FEV}_{1}$ decline. From above cited studies on AHR and $\mathrm{FEV}_{1}$ decline. From
this exercise we should appreciate that merely studying exposures and $\mathrm{FEV}_{1}$ decline in adult life is insufficient (Weiss, personal communication). Thus, AHR and perhaps atopy (the core components of the "basic disturbances" described by Orie et al) could link early life its purest form exemplified by the seminal study by Fletcher and coworkers of London transport workers. ${ }^{45}$ In parallel, COPD research will enquire into the underlying mechanisms - for example, research into oxidative pulmonary stress-but whether future research will ever again lead to a single aetiological hypothesis remains to be seen.

Conclusions

We conclude that the "Dutch hypothesis" is still with us. After more than 35 years of increasing awareness of COPD and increasing research, the "hypothesis" is now being tested. Its components and the ideas behind it are playing an influential and important role in understanding the underlying mechanisms of chronic airflow limitation.

1 Orie NGM, Sluiter HJ, de Vries $\mathrm{K}$, et al. The host factor in bronchitis. In: Orie NGM, Sluiter HJ, eds. Bronchitis: an international symposium. Assen, Netherlands: Royal van Gorcum, 1961

'Connor GT, Spand Deiss ST. The role of allergy and nonspecific airway hyperresponsiveness in the pathogenesis of chron
pulmonary disease. Am Rev Respir Dis 1989;140:225-52

Pride NB, Burrows B. Development of impaired lung function: natural anter obstructive pulmonary disease. London: Chapman \& Hall, 1995.
Anthonisen NR, Connett JE, Kiley JP, et al. Effects of smoking intervention and the use of an inhaled anticholinergic bronchodilator on
the rate of decline of $\mathrm{FEV}_{1}$ : the Lung Health Study. FAMA 1994; the rate of dect

5 Tashkin DP Altose MD, Bleecker ER, et al, for the Lung Health Study Research Group. The Lung Health Study: airway hyperresponsivenes to inhaled methacholine in smokers with mild to moderate airflow

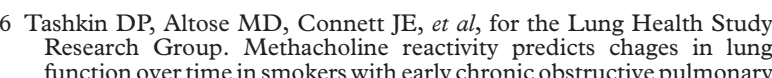
Research Group. Methacholine reactivity predicts chages in lung
disction over time in smokers with early chronic obstructive pulmonary
dis f Respir Crit Care Med 1996;153:1802-11. disease. Am F Respir Crit Care Med 19961153:1802-11.
7 Du Toit JI, Woolcock AJ, Salome CM, et al. Characteristics of bronchial hyperresponsiveness in smokers with chronic airflow limitation. Am
Rev Respir Dis 1986;134:498-501. Higgins BG, Britton JR, Chinn S. Comparison of histamine and methaThorax 1988;43:605-10.
chalial che tests in community studies. $9 \begin{gathered}\text { Rijcken B, Shouten JP, Weiss ST, et al. The relationship of nonspecific } \\ \text { bronchial responsiveness to respiratory symptoms in a random popu- }\end{gathered}$ bronchial responsiveness to respiratory symptoms in a random popu-
lation sample. Am Rev Respir Dis 1987; 136:62-8. lation sample. Am Rev Respir Dis 10 , al. The relationship of nonspecific
Sparrow D, O'Connor G, Colton T, et al bronchial responsiveness to the occurrence of respiratory symptoms
and decreased levels of lung function. Am Rev Respir Dis 1987;135: $1255-60$.
Rijcken B

airway responsiveness to Weiss ST, et al. The relationship between a random population sample. Am Rev Respir Dis 1988;137:826-32. hyperresponsiveness and asthma in a rural adult population. Thorax

1987;42:361-8.
13 Bakke PS, Baste V, Gulsvik A. Bronchial responsiveness in a Norwegian

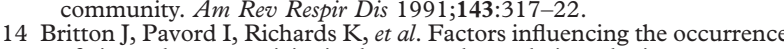
of airway hyperreactivity in the general population: the importance of atopy and airway calibre. Eur Respir $\mathcal{Y} 1994 ; 7: 881-7$.
Peat JK, Salome CM, Xuan W. On adjusting me. Peat JK, Salome CM, Xuan W. On adjusting measurements of airways
responsiveness for lung size and airway caliber. Am $\mathcal{F}$ Respir Crit Car
Med 1996;154:870-5.

6 Rijcken B, Scouten JP, Xu X, et al. Bronchial hyperresponsiveness to Crit Care Med 1995;151:1377-82.

17 Villar MT, Dow L, Coggon D, et al. The influence of increased bronchial responsiveness, atopy, and serum IgE on decline in $\mathrm{FEV} \mathrm{V}_{1}$ 151:656-62.

18 Parker DR, O'Connor GT, Sparrow D, et al. The relationship of nonspecific airway responsiveness and atopy to the rate of decline of lung function. The Normative Aging Study. Am Rev Respir Dis 1990;
O'Connor GT, Sparrow D, Weiss ST. A prospective study of metha-

19 O'Connor GT, Sparrow D, Weiss ST. A prospective study of methacholine airway responsiveness as a predictor of pumed Care Med 1995;
decline: the Normative Aging Study. Am ₹ Respir Crit
152:87-92.

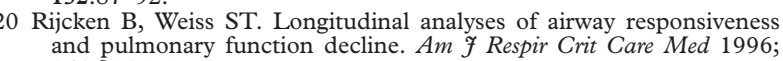
154:S246-9. Irwig LM, Groeneveld HT, Becklake MR. Assessing the effect of exposure on lung function loss between two occasions: issues of
confounding and measurement error. In: Hensley MJ, Saunders NA, eds. Clinical epidemiology of chronic obstructive pulmonary disase. New eds. Clinical eppidemiology of ch

22 Kerstiens HAM, Rijcken B, Schouten JP, et al. Decline of $\mathrm{FEV}_{1}$ by age
and smoking status: facts, figures, and fallacies. Thorax 1997;52: Gold DR, Wang X, Wipyj D, et al. Effects of cigarette smoking on lun function in adolescent boys and girls. N Engl F Med 1996;335:931-7. 4 Kelly WJW, Hudson I, Raven J, et al. Childhood asthma and adult lung function. Am Rev Respir Dis 1988;138:26-30.
Tager IB, Segal MR, Speizer FE, et al. The natural history of forced expiratory volumes. Effect of cigarette smoking and respiratory symptoms. Am Rev Respir Dis 1988;138:837-49.

26 Robbing Dadults: is there a plateau phase? Eur Restion development in

27 Preung adults: is there a plateau phase? Eur Respir $\mathcal{F}$ 1995;8:768-72. smoking effects on lung function and risk of hospitalization for COPD: results from a Danish longitudinal population study. Eur Respir $f$.
1997;10:822-7. 28 Prescott E, Osler M, Andersen PK, et al. Mortality in women and men
in relation to smoking. Results from the Copenhagen Center for 29 Kanner RE, Connett JE, Altose MD, et al, for the Lung Health Study Research Group. Gender difference in airway hyperresponsiveness in smokers with mild COPD: the Lung Health Study. Am f Respir Crit 
30 Leynaert B, Bousquet J, Henry C, et al. Is bronchial hyperresponsiveness
more frequent in women than in men ? A population-based study. more frequent in women than in men ? A population-based study.
Am $\mathcal{F}$ Respir Crit Care Med 1997;156:1413-20. Vestbo J, Prescott E, Lange P, and The Copenhagen City Heart Study
Group. Association of chronic mucus hypersecretion with FEV 1 de-
cline and COPD morbidity. Am f Respir Crit Care Med 1996;153: $1530-5$.
Sherman $\mathrm{CB}, \mathrm{Xu} \mathrm{X}$, Speizer FE, et al. Longitudinal lung function decline in subjects with respiratory symptoms. Am Rev Respir Dis 1992;146:855-9.
Thompson AB, Daughton D, Robbins R, et al. Intraluminal airway inflammation in chronic bronchitis. Am Rev Respir Dis 1989;140: 34 Saetta $M$, Finkelstein R, Cosio MG. Morphological and cellular basis 35 British The liactic Son th 35 Bitsh Thoracic Society. Guidelines for the management of chronic obstructive pulmonary disease. Thorax 1997,52 (Suppl 5$):$ S1-28.
asthen B, Schouten JP., Rosner B, et al. Isit useful to distinguish between
asthma and chronic obstructive pulmonary disease in respiratory

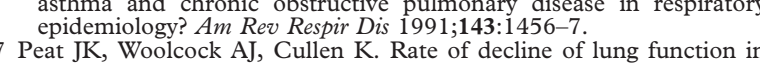

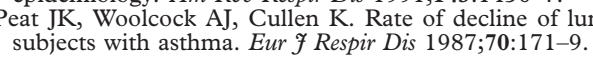

38 Ulrik CS, Backer V, Dirksen A. A 10 year follow up of 180 adults with bronchial asthma: factors important for the decline in lung function. Thorax 1992;47:14-8.
Ulrik CS, Lange P. Decline of lung function in adults with bronchial 39 Ulrik CS, Lange P. Decline of lung function in adults with bronchial
asthma. Am ₹ Respir Crit Care Med 1994;150:629-34. 40 Lange P, Ulrik CS, Vestbo J, for The Copenhagen City Heart Study sroup. Mortality in adults with self-reported bronchial asthma. A
sarker DJ, Godfreral population. Lancet 1996;371:1285-9. Barker DJ, Godfrey KM, Fall C, et al. Relation of birth weight and
childhood respiratory infection to adult lung function and death from childhoodic obstructive airways disease. BMY $1991 ; 303$ a $671-5$.
Stein $\mathrm{CE}$, Kumaran $\mathrm{K}$, Fall $\mathrm{CH}$, et al. Relation of fetal growth to adult Stein CE, Kumaran K, Fall CH, et al. Relation of fetal growth to adult Britton J, Martinez FD. The relationship of childhood respiratory infection to growth and decline in lung function. Am f Respir Crit
Care Med 1996;154:S240-5. 44 Weiss ST, Segal MR, Tager IB, et al. The effects of asthma on pulmonary
function in children: a longitudinal population-based study. $A m$ Rev Respir Dis 1992;145: 58-64. Fletcher CM, Peto R, Tinker CM, et al. The natural history of chronic
bronchitis and emphysema. Oxford: Oxford University Press, 1976. 